\title{
Diversity In Television Commercials: A Content Analysis
}

Susan Baxter, (E-mail: baxters@cookman.edu), Bethune-Cookman College

\begin{abstract}
To increase market penetration, businesses work on engaging current and new customers to purchase additional products via creating a market offering to match the needs of the consumer group. "Failure to recognize the reality of market segments was resulting in the loss of market position" (Smith, 1956, p. 5) for companies. Smith (1956) notes that the successful application of the strategy of market segmentation "tends to produce depth of market position in the segments that are effectively defined and penetrated" ( $p .5)$. The United States, with a history of being the world's melting pot, is a multicultural society. Differences between rich, poor, urban and rural Americans have been augmented by racial and ethnic diversity (Riche, 1991). Successful utilization of this diversity has been of concern to business. This paper analyzed 177 commercials to determine the proportion of inclusiveness in regards to gender, age, race, and language. Diversity in gender and race was demonstrated, but improvement is needed in race, age, and language.
\end{abstract}

\section{INTRODUCTION}

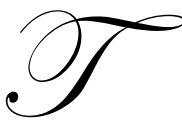

he United States, with a history of being the world's melting pot, is a multicultural society. Differences between rich, poor, urban and rural Americans have been augmented by racial and ethnic diversity (Riche, 1991). Successful utilization of this diversity has been of concern to business. To increase market penetration, businesses work on engaging current and new customers to purchase additional products via creating a market offering to match the needs of the consumer group. "Failure to recognize the reality of market segments was resulting in the loss of market position" (Smith, 1956, p. 5) for companies. Smith (1956) notes that the successful application of the strategy of market segmentation "tends to produce depth of market position in the segments that are effectively defined and penetrated" (p. 5).

Target marketing has become increasingly important in marketing strategy, especially given the amount of increasing diversity in populations (Martin, Lee, \& Yang, 2004, Grier \& Brumbaugh, 1999). Target marketing, and segmenting of markets, is not new. Marketing segmentation was introduced by Smith and has become a staple in marketing management (Smith, 1956). Segmentation is an accepted tool of management and considered one of the foremost means of operationally defining the marketing concept. Marketing managers continuously try to enhance programs that make as efficient use of the firm's resources as possible; consequently, the strategy of market segmentation has become widely utilized and accepted (Elrod \& Winer, 1982). Segmentation is a way to identify homogenous groups within a market in order to develop unique value propositions matching the segment's needs (Crosby \& Johnson, 2004). The fundamental proposition of segmentation is that not all consumers are equal; consumers have to be diverse in order for segmentation to be cost-effective. Marketers using segmentation strategies attempt to deliver value to a specific subset of consumers who share similar demands (Fugate, 1993). Segmentation provides guidelines for a firm's marketing strategy and resource allocation among markets and products (Wind, 1978).

"Increased target marketing has been touted as a response to marketplace diversity" (Grier \& Brumbaugh, 1999, p. 79). The changing face of the marketplace, particularly regarding ethnicity, is impacting marketing strategies with increased target marketing including expanding representation of ethnic groups in advertising (Zinkhan, Quall, \& Biswas, 1990, Martin, Lee, \& Yang, 2004). The United States is becoming a multicultural society. The population in the United States is changing, just as rapidly as the rest of the world. "The differences between rich, poor, urban, and rural Americans are being increased by racial and ethnic diversity" (Riche, 1991, p. 26). By 2050, half of the U.S. 
will be people of color (Johnson, 2005). During the 1990s and beyond, the U.S. will shift from a society dominated by whites and rooted in Western culture to a world society characterized by three large racial and ethnic minorities: blacks, Hispanics, and Asians (Riche, 1991). Given this information, one assumes that marketers would attempt to reach a wider audience through more diverse campaigns. This paper examines a snapshot of television commercials in the top 4 rated television shows during one week to determine if there is, in fact, population diversity in commercials. "Documenting the trend in the portrayal of racial minorities on prime time television serves two major purposes...it is socially significant to identify the extent to which television networks represent U.S. ethnic minorities" (Mastro \& Greenberg, 2000, p. 690).

\section{PROBLEM STATEMENT}

Given these trends, the diversity in marketing campaigns continues to be a critical issue. Marketing managers recognize that in order for the product to be profitable, maximizing effectiveness of target marketing is crucial. In today's competitive marketplace, effectively utilizing mass communication media to promote products or services to a large group of consumers can give businesses a competitive advantage. It is the purpose of this study to investigate ways in which diversity of consumers are communicated through television commercials. The following sections of this paper will review applicable literature on the subject in an effort to expand on the discussion of diversity in marketing and the utilization of the television commercials as an effective marketing tool for reaching diverse markets.

\section{LITERATURE REVIEW}

There have been numerous studies over the years that examine the inclusion of minorities in advertising campaigns. These studies have focused on various aspects of diversity, including the roles assigned to genders and races, the effects of ethnically diverse advertisements on both the target market and the non-target market, using unattractive people in advertisements, and products/services advertised based on gender and race, just to name a few (Coltrane \& Messineo, 2000, Whittler, 1991, Bristor, Gravois, \& Hunt, 1995, Singer, 1983).

Marketing and advertisement professionals focus their efforts on consumers' wants and needs. They monitor what consumers are thinking. In the early 1960s, researchers were examining the impact of including blacks in advertisement and marketing materials for products aimed at whites. One study looked at attitudinal responses between integrated and non-integrated promotional stimuli (Barban \& Cundiff, 1964). Barban and \& Cundiff's (1964) results demonstrated that white's response to ads with black models was either neutral of slightly positive. Before this time, marketing was very segregated - products marketed to the black community used black models in black media (billboards in black neighborhoods, black magazines, black newspapers). White models were used for all commercials on television and in the advertisements in mainstream magazines and newspapers.

Other researchers used the methodology from the Barban \& Cundiff study to examine the effects of different levels of social intimacy using integrated models (Barban, 1969), the level of the subject's prejudice (Cagley \& Cardozo, 1970), the effect of the advertisement on the product advertised (Muse, 1971, Stafford, Birdwell \& Van Tassell, 1970), and the impact on consumer brand loyalty when using integrated promotional materials (Block, 1972). These studies focused primarily on print media advertisement.

The first major study of blacks in television commercials examined the inclusion level, including the types of products advertised, whether the commercial was integrated, and what genders were represented (Hair, Solomon, \& Bush, 1977, Bush, Hair, \& Solomon, 1979). "The impetus for this research was marketers' wish to design strategies to appeal to the growing black market without alienating the dominant white market" (Bush, Hair, \& Solomon, 1979, p. 341). As minority groups become more influential, as demonstrated by increased buying power, marketers take notice and attempt to target that burgeoning group without offending the current consumer base.

One would hope that popular culture, as represented by television commercials, has demonstrated a realistic portrayal of the various ethnic and racial groups that comprise our population. However, there has been ongoing research, via content analysis, to determine the level of inclusion of ethnic groups, genders, and age diversity and 
found it to fall short (Bristor, Gravois, \& Hunt, 1995, Coltrane \& Messineo, 2000, Qualls \& Moore, 1990). Considering that "individuals process ads subjectively on the basis of their membership in groups defined by ethnicity or gender, or their life themes or experiences", one would think that marketers would work to change inclusion levels with identified buying power levels (Bhat, Leigh, \& Wardlow, 1998, p. 9).

Culture and gender differences are displayed in modern media outlets. The television entertainment industry has been accused of being a producer and promoter of stereotypes and prejudicial attitudes (Coltrane \& Messineo, 2000). The authors noted that television producers have segmented audiences so that advertising could be created to reach each separate group. Television helped create lifestyle segmentation based on income and ethnicity. "Although segmented markets can engender a tight sense of community among people who share similar backgrounds, such differentiation can also promote suspicion of others" (Coltrane \& Messineo, 2000, p. 367). The authors noted that while television was attempting to be "inclusive during the 1990s, commercials reproduced many stereotypes of race and gender" (Coltrane \& Messineo, 2000, p. 385). Turow (1997) blames segmentation strategies for increasing racial tensions during the latter twentieth century. Wilson \& Gutierrez (1995) suggest that television once acted to bring people together, it now appears to reinforce the differences that keep them apart.

Culture has become a recent research love for marketers. Since the early 1990's, various studies have been completed on the viability of the Hispanics, Asians, and Haitians as marketing segments due to their culture (Lindridge \& Dibb, 2003). The authors utilized a comparative quantitative study examining a range of cultural values and their impact on buying behavior of British Indians and British Caucasians. Lindridge \& Dibb (2003) found that, in this study, culture could not be used as a segmentation variable due to similarities between the two groups. While the study did not deliver the result hoped for, there are significant contributions to the discipline via future study opportunities and the strong statement that "marketer's specifically striving to serve the needs of an ethnic group will need to properly understand the behavior, expectations, needs and perceptions of their target market's customers" (p. 282).

Gender representation in television commercials is another area of population diversity that has been studied throughout the years. Bartsch, Burnett, Diller, and Rankin-Williams (2000) conducted an update on the status of gender representation by replicating the studies of O'Donnell and O'Donnell from 1978 and Lovdal's 1989 study. A total of 757 commercials from spring 1998 were analyzed for product type, gender of product representative, and gender of voice-over (Bartsch, Burnett, Diller, \& Rankin-Williams, 2000). Unequal gender representation as demonstrated by an overrepresentation of females as domestic product representatives and males as non-domestic product representatives were found (Bartsch, Burnett, Diller, \& Rankin-Williams, 2000).

A demographic that is being examined more often is ethnicity. Romero and Wilson (1998) take up the cause of multicultural consumers. The authors report, "in 1990, the purchasing power of African-Americans, Hispanic Americans, Asian-Americans, American Indians and Pacific Islanders was nearly $\$ 600$ billion” (p. SS2). Diverse consumers are a possible marketplace for companies that want to stay competitive. However, the authors point out "in 1996, nearly $\$ 170$ billion was spent on advertising and of that only $1 \frac{1}{2} 2$ percent was aimed at multicultural markets" (p. SS2). The authors further point out that the Hispanic consumer market has doubled since 1990. While the demographics show that multicultural markets are a financially viable option, marketers, as evidenced by the advertising expenditures, have not yet maximized them

Chudry and Pallister (2002) also take up the ethnicity as segmentation criterion. They studied ethnic groups in the United Kingdom and the group's reaction to direct mail marketing. This study looked at the Pakistani community in the United Kingdom, which is the second largest ethnic group in that country. The authors utilized focus groups, face-to-face interviews and a mail questionnaire (survey), which had a response rate of 22\% (2002). The results of the survey were analyzed via univariate analysis, bi-variate analysis, and factor analysis. The results demonstrated that this population feels positive about direct mail marketing that is accurately targeted and interesting. The Pakistani's in Britain "wish to be targeted according to their ethnicity" (p. 125). 
Forehand and Deshpande (2001) proposed that consumers' awareness of their membership in social groups (and potentially felt distinctiveness based on membership) may be brought forth by execution factors in a targeted advertisement as well as contextual primes that precede exposure to the targeted advertisement. They discussed ethnic self awareness which is defined as a temporary state during which a person is more sensitive to his or her ethnicity and this temporary state can be primed by cues in advertising and consumption situations. The authors hypothesized that ethnic primes in an advertisement would elicit ethnic self awareness and prompt more favorable attitudes toward same ethnicity actors featured in ethnically targeted advertisements (in-group bias).

As discussed earlier, there has been research into the effectiveness and consequences of using different models in various advertising. The research has primarily been focused on the use of African-American models, however with the increasing attractiveness of other minority groups to marketers, there have been an increase in minority representation in commercials. Cohen (1992) examined the reaction of white consumers to Asian models. "Asian-Americans, as a group, have higher income, education, and occupational status than the average American" (Cohen, 1992, p. 18). Due to fragmentation of Asian media outlets, it is recommended that marketers attempt to reach this consumer group through mainstream outlets (Cohen, 1992). Martin, Lee, and Yang (2004) looked at ad model ethnicity and self-referencing and how they influenced attitudes toward a product or service utilizing Asian models. Asian consumers relate ads to themselves in higher amounts (than whites) when viewing an Asian model (Martin, Lee, \& Yang, 2004).

Wilkes and Valencia (1989) examined whether or not Hispanics and blacks were included in advertisements that were not specifically targeted for minority customer markets. Prior research noted that there has been a steady increase of blacks in television commercials since 1965 (Wilkes \& Valencia, 1989). "Research reveals a virtual absence of Hispanics from television programming" and virtually no Hispanics have been reported in television commercials (Wilkes \& Valencia, 1989, p. 20). Wilkes \& Valencia conducted research studying 63 hours of prime time television programming during the late 1980s. The authors noted Hispanics appeared in half as many product categories as blacks and Hispanics appeared in substantially fewer prime time network television commercials than did blacks (Wilkes \& Valencia, 1989).

Qualls and Moore (1990) looked at in-group bias theory and how it influenced viewer attitudes of advertising. This research provides an in-depth discussion of the impact of racial stereotyping in advertising. Utilizing the information in this study, marketing managers can predict the effectiveness of advertising campaigns targeted to both minority and non-minority consumers (Qualls \& Moore, 1990). "Marketing practitioners should place more emphasis on targeting racial subgroups when developing marketing and advertising campaigns, making sure that actors used in ads targeted for market segments based on race use members of that target group" (Qualls \& Moore, 1990, p. 149)

A final area of study regarding diversity represented in advertising is age. Age is used as a market segmentation strategy for many products, including television shows. Older people are rarely seen in advertisements and commercials (Singer, 1983). "Most people are not glamorous, many are over age 60 or members of visible minority groups" therefore using real people - or accurate representations of real people - in commercials can positively impact the effectiveness of an advertising campaign (Singer, 1983, p. 36).

\section{RESEARCH QUESTIONS}

Why is it important to examine diversity in television commercials? Many researchers state that advertising plays a role in reducing (or increasing) racial prejudice based on the leveling of cultural and gender differences (Bush, Gwinner, \& Solomon, 1974, Coltrane \& Messineo, 2000). Consumer attitude towards an advertisement, and subsequently towards the product or service promoted in that advertisement, are impacted by the ability of the consumer to view themselves as similar or dissimilar to the users of that product or service. "It follows that when consumers of a particular ethnic minority perceive an ethnic similarity between themselves and an advertising model of a similar ethnicity, this judgment will result in self-referencing" (Martin, Lee, \& Yang, 2004, p. 28). "In-group members will evaluate other in-group members more favorably than they will out-group members" (Qualls \& Moore, 1990, p. 148) 
The focus of this study is to examine the amount of diversity present in prime time television commercial advertisements by looking specifically at the top four Nielsen rated shows and examining gender, age, and race of the models in the commercials.

Null hypothesis: There is not diversity present in prime time television commercials, as represented by age, gender, accent, and race/ethnicity of models.

Alternative hypothesis: There is diversity present in prime time television commercials, as represented by age, gender, accent, and race/ethnicity of models.

\section{METHODOLOGY}

The overall purpose of the study is to describe the degree to which population diversity is present in televised commercials. The research design necessitates the utilization of a descriptive research study. Descriptive research is a "type of conclusive research that has as its major objective the description of something - usually market characteristics or functions" (Malhotra, 2004, p. 78). To achieve this content analysis was the method utilized.

Why content analysis? Several prior studies have utilized content analysis to determine the level of diversity in commercial advertising (Bristor, Gravois, \& Hunt, 1995, Coltrane \& Messineo, 2000, Qualls \& Moore, 1990). Content analysis allows for a systematic, objective, and quantifiable analysis of message characteristics. This methodology is applicable to many areas of study, and is the fastest growing technique used in mass communications research (Neuendorf, 2001). Content analysis dictates the use of an a priori design as variables, measurements, and coding methods are determined before any observations take place. This increases objectivity in the design.

A content analysis was conducted on television commercials that aired on broadcast television during midNovember 2005. The sample was selected via choosing the top five Nielsen rated shows during mid-November, with the idea since the highest rated shows garnered the largest audience sizes across gender, age, and race. One show was a sporting event (Monday Night Football) and was discarded due to the difference in length of airtime for the show. The other four shows were all one hour in length. The sample consisted of 177 commercials. The dependent variable is the commercial, and the independent variables are the models used within the commercials (or used for voice overs).

The data collection tool was broken down into sections: Gender, Product, Age [child, pre-teen, teen/young adult, adult, retiree/elderly], Race [white, black, Hispanic, Asian, mixed], Accent [presence of an accent, no accent]. Originally, additional information was also categorized to include product being advertised, setting, relationship to product, behavior displayed by models in advertisement, family status, and affective state displayed. These combinations of variables were used by Mastro and Stern (2003). However, the scope of this article is examining only inclusiveness of diverse populations, and not the wider reaching scope of study that larger research projects have included. Therefore, the variables examined were limited to gender, age, race, and accent.

The television commercial codebook used to analyze the commercials is available in the appendix to this article. An outside reviewer examined the codebook to insure face validity of the collection tool. The top rated television shows were recorded to allow for playback and review of commercials. Three coders were used to collect data by counting occurrences of diversity in the televised commercials. The decision to use three coders in data collection was made for two reasons: (1) expedite the process, and (2) ensure reliability of the measurement tool. Having the commercials recorded allowed the coders the opportunity to revisit any commercials that had a discrepancy in evaluation. Simple agreement in the coding was determined by using Hosti's formula with a result of 0.85 demonstrating intercoder reliability. 


\section{DATA ANALYSIS}

The data demonstrates that males continue to be the more represented gender in commercials, as related to numbers of men in commercials with 353 men in 177 commercials versus 306 females in 177 commercials. However, women were represented in $80.8 \%$ of all commercials reviewed, while men were present in $78.6 \%$ of all commercials viewed. Of the 177 commercials viewed, $9 \%$ had neither gender represented. These results represent a change in prior research, which found men dominating the commercials (Coltrane \& Messineo, 2000, Bartsch, Burnett, Diller, \& Rankin-Williams, 2000).

The following table denotes the breakdown of models in commercials by age group. You will note that some commercials had several ages represented, as demonstrated by the frequencies.

Table 1

Frequency and Percentages of ages of models represented in commercials

\begin{tabular}{|c|c|}
\hline Age & Frequency \\
\hline Child & 24 \\
\hline Pre-teen & 18 \\
\hline Teen/young adult & 11 \\
\hline Adult & 159 \\
\hline Elderly & 6 \\
\hline Total Commercials & 177 \\
\hline
\end{tabular}

This information coincides with prior research that primarily adults are used in commercials and elderly are "hidden" (Singer, 1983).

The next area to consider is the race of the models used in advertising. Table 2 outlines the inclusiveness of the commercials viewed. Several commercials utilized a variety of races within the commercial. However, $45.8 \%$ of the commercials utilized only whites in the advertisement. Whites overall are represented disproportionately with a frequency ratio of 0.853 , yet blacks have gained with $30 \%$ (from $12.3 \%$ reported by Mastro \& Stern, 2003). According to the U.S. Census (2000), Latinos (Hispanics) make up $12.5 \%$ of the U. S. Population, and they were represented $19.2 \%$ of the time in commercials viewed. This represents a gain from prior research (Mastro \& Stern, 2003, Wilkes \& Valencia, 1989). According to the U.S. Census (2000), Asians represent approximately $4 \%$ of the U.S. population. In this study, Asians frequented commercials in a 0.091 ratio. Mixed race, a catchall category, comprised $28.3 \%$ of the models used in the commercials viewed for this study.

Table 2

Race of models used in commercial advertisements

\begin{tabular}{|c|c|}
\hline Race & Frequency \\
\hline White/Caucasian & 151 \\
\hline Black/African-American & 53 \\
\hline Hispanic & 34 \\
\hline Asian & 16 \\
\hline Mixed & 50 \\
\hline
\end{tabular}

The final area examined was diversity through language, as demonstrated by the presence of an accent in a speaking role in the commercial. An accent was prevalent during 26 of the commercials viewed, for a frequency proportion of 0.147 . Given the multicultural nature of the current population of the U.S., this figure is very low.

This study has demonstrated diversity in several areas of interest: gender (at almost 50\% for each gender), and race (an increase found in all categories compared to prior research). Improvement is still needed in age diversity and language diversity. Based on the data, we have not supported the null hypothesis, as diversity was evident in the television commercials viewed. 


\section{CONCLUSION}

As previously noted, the purpose of this study was to demonstrate whether television commercials during prime time demonstrated diversity in the models used to promote products and services. "In a multicultural society, businesses thrive by finding common ground across racial and ethnic groups" (Riche, 1991, p. 29). Progress has been noted in the representation of various groups. However, there is still room for improvement. According to Robertson, Zielinski, and Ward (1984) "For most products the best way to reach a subculture is through advertising in the mass media" (as cited in Wilkes \& Valencia, 1989, p. 19). Reaching that subculture is easier if the subculture finds something to identify with in the advertisement - a similar looking person, setting or language, for example.

Advertisements play a large role in today's society. "Researchers argue that the sheer pervasiveness of advertising may enhance its potential to influence television viewers" (Mastro \& Stern, 2003, p. 638). Advertising can make or break stereotypes (Singer, 1983, Bartsch, Burnett, Diller, \& Rankin-Williams, 2000, Grier \& Brumbaugh, 1999). Advertising can enhance attitudes among subcultures and break down societal misperceptions about the targeted segment (Grier \& Brumbaugh, 1999). Therefore, inclusiveness in advertising can be equated with societal marketing. "Advertisers seeking to employ inclusive ad campaigns are advised to avoid stereotypic imagery in favor or an emphasis on common human concerns, needs, and benefits" (Bhat, Leigh, \& Wardlow, 1998, pp. 23-24).

\section{LIMITATIONS}

This research has several limitations. First, the sample size is very small in comparison to other studies conducted. Second, while the commercials on top rated shows were examined, alternative networks that target minority markets were not researched to determine the level of inclusiveness in advertisements on those channels. Third, this research did not examine the roles assigned to the models in the commercials. This is an area of concern, and has been researched in the past. Updated research which includes not only the level of inclusiveness of diverse populations, but the roles and products those models utilize could help further the discussion of adequate representation of various consumer groups on television.

\section{REFERENCE}

1. Barban, A. M. (1969). The dilemma of integrated advertising. Journal of Business of the University of Chicago, 42, pp. 477-496

2. Barban, A. M. \& Cundiff, E. W. (1964). Negro and white response to advertising stimuli. Journal of Marketing Research, 1, pp. 53-56.

3. Bartsch, R. A., Burnett, T., Diller, T. R., \& Rankin-Williams, E. (2000). Gender representation in television commercials: updating an update. Sex Roles, 43(9/10), 735-743.

4. Bhat, S., Leigh, T.W., \& Wardlow, D. L. (1998). The effect of consumer prejudices on ad processing: heterosexual consumers' responses to homosexual imagery in ads. Journal of Advertising, 27(4), 9-25.

5. Block, C. E. (1972). White backlash to Negro ads: fact or fantasy? Journalism Quarterly, 49, pp. 258-262.

6. Bristor, J. M. L., Gravois, R., \& Hunt, M. R. (1995). Race and ideology: African-American images in television advertising. Journal of Public Policy \& Marketing, 14(1), 48-59.

7. Bush, R. F., Gwinner, R. F., \& Solomon, P. J. (1974). White consumer sales response to black models. Journal of Marketing, 38(1), 25-29.

8. Bush, R.F., Hair, J. F., \& Solomon, P. J. (1979). Consumers' level of prejudice and response to black models in advertisements. Journal of Marketing Research, 16(3), 341-345.

9. Cagley, J. W. \& Cardozo, R. N. (1970). White responses to integrated advertising. Journal of Advertising Research, 10, pp. 29-33.

10. Chudry, F. \& Pallister, J. (2002, December). The importance of ethnicity as a segmentation criterion: the case of the Pakistani consumers' attitude towards direct mail compared with the indigenous population. Journal of Consumer Behavior, 2(2), 125-137.

11. Cohen, J. (1992). White consumer response to Asian models in advertising. The Journal of Consumer Marketing, 9(2), 17-27. 
12. Coltrane, S. \& Messineo, M. (2000). The perpetuation of subtle prejudice: race and gender imagery in 1990s television advertising. Sex Roles, 42(5/6), 363-389.

13. Crosby, L.A., \& Johnson, S. L. (2004). Redefine your customer base. Marketing Management, 13(2), 12-13.

14. Elrod, T. \& Winer, R. S. (1982). An empirical evaluation of aggregation approaches for developing market segments. Journal of Marketing, 46(4), 65-75.

15. Forehand, M. R. \& Deshpande, R. (2001). What we see makes us who we are: priming ethnic self-awareness and advertising response. Journal of Marketing Research, 28, pp. 336-348.

16. Fugate, D. L. (1993). Evaluating the US male homosexual and lesbian population as a viable target market segment. Journal of Consumer Marketing, 10(4), 46-57.

17. Grier, S. A. \& Brumbaugh, A. M (1999). Noticing cultural differences: Ad meanings created by target and non-target markets. Journal of Advertising, 28(1), 79-93.

18. Hair, J. F., Solomon, P. J., \& Bush, R. F. (1977). A factor analytic study of black models in television commercials. The Journal of Business, 50(2), 208-215.

19. Johnson, A. D. (2004, March 18). In 2050, half of U.S. will be people of color. Diveristy Inc. Retrieved December 7, 2005 from the World Wide Web at http://www.diversityinc.com/members/6550.cfm

20. Lindridge, A. \& Dibb, S. (2003, March). Is 'culture' a justifiable variable for market segmentation? A crosscultural example. Journal of Consumer Behavior, 2(3), 269-286.

21. Malhotra, N. K. (2004). Marketing Research: An Applied Orientation (4 ${ }^{\text {th }}$ ed.). Upper Saddle River, New Jersey: Prentice Hall

22. Martin, B. A. S., Lee, C. K-C., \& Yang, F. (2004). The influence of ad model ethnicity and self-referencing on attitudes. Journal of Advertising, 33(4), 27-37.

23. Mastro, D. E. \& Greenberg, B. S. (2000). The portrayal of racial minorities on prime time television. Journal of Broadcasting \& Electronic Media, 44(4), 690-702.

24. Mastro, D. E. \& Stern, S. R. (2003). Representations of race in television commercials: a content analysis of prime-time advertising. Journal of Broadcasting \& Electronic Media, 47(4), 638-647.

25. Muse, W. V. (1971). Product-related response to use of black models in adverting. Journal of Marketing Research, 8, pp. 107-109.

26. Neuendorf, K. A. (2001). The content analysis guidebook. Thousand Oaks, CA: Sage Publications.

27. Qualls, W. J. \& Moore, D. J. (1990). Stereotyping effects on consumers' evaluation of advertising: Impact of racial differences between actors and viewers. Psychology \& Marketing, 7(2), 135-151.

28. Riche, M. F. (1991). We're all minorities now. American Demographics, 13(10), 26-31.

29. Romero, E. \& Wilson, L. (1998). Advertisers unaware of markets' reach. Colorado Business, $25(1)$, p. SS2.

30. Singer, B. D. (1983). The case for using real people in advertising. Business Quarterly, 48(4), 32-37.

31. Smith, W. (1956). Product differentiation and market segmentation as alternative marketing strategies. Journal of Marketing, 21(1), 3-8.

32. Stafford, J. E., Birdwell, A. E., \& Van Tassel, C. E. (1970). Integrated advertising - white backlash. Journal of Advertising Research, 10, pp. 15-20.

33. Turow, J. (1997). Breaking up America: Advertisers and the new media world. Chicago: University of Chicago Press.

34. U.S. Census. (2000). Retrieved December 14, 2005 from http://www.census.gov/population

35. Whittler, T. E. (1991). The effects of actors' race in commercial advertising: review and extension. Journal of Advertising, 20(1), 54-60.

36. Wilkes, R. E. \& Valencia, H. (1989). Hispanics and blacks in television commercials. Journal of Advertising, 19(1), 19-25.

37. Wilson, C. C. \& Gutierrez, F. (1995). Race, multiculturalism, and the media. Thousand Oaks, CA: Sage.

38. Wind, Y. (1978). Issues and advances in segmentation research. Journal of Marketing Research, 25, (3), 317-337.

39. Zinkhan, T., Qualls, W. J., \& Biswas, A. (1990). The use of blacks in magazines and television advertising: 1946 to 1986. Journalism Quarterly, 67(3), 547-553. 


\section{Appendix}

\section{Codebook}

Show viewed:

Date show aired:

\begin{tabular}{|c|c|c|}
\hline Gender & Male & \\
\hline & Female & \\
\hline Number of people in commercial & & \\
\hline Age & Child & \\
\hline & Pre-teen & \\
\hline & Teen-young adult & \\
\hline & Adult & \\
\hline & Retiree age/Elderly & \\
\hline & White & \\
\hline Race & Black & \\
\hline & Hispanic & \\
\hline & Asian & \\
\hline & Other/mixed & \\
\hline & Presence & \\
\hline & Absence & \\
\hline & & \\
\hline & & \\
\hline & &
\end{tabular}




\section{NOTES}

